\title{
Electrical and optical properties of SnEuTe and SnSrTe films
}

\author{
Akihiro Ishida, ${ }^{1, a)}$ Takuro Tsuchiya, ${ }^{1}$ Tomohiro Yamada, ${ }^{1}$ Daoshe Cao, ${ }^{1}$ Sadao Takaoka, ${ }^{2}$ \\ Mohamed Rahim, ${ }^{3}$ Ferdinand Felder, ${ }^{3}$ and Hans Zogg ${ }^{3}$ \\ ${ }_{1}^{1}$ Faculty of Engineering, Shizuoka University, Johoku 3-5-1, Naka-ku, Hamamatsu 432-8561, Japan \\ ${ }^{2}$ Department of Physics, Graduate School of Science, Osaka University, Machikaneyama 1-1, \\ Toyonaka 560-0043, Japan \\ ${ }^{3}$ Thin Film Physics Group, ETH Zurich, Technopark, CH-8005 Zurich, Switzerland
}

(Received 25 March 2010; accepted 9 May 2010; published online 18 June 2010)

\begin{abstract}
The $\mathrm{SnTe}, \mathrm{Sn}_{1-\mathrm{x}} \mathrm{Eu}_{\mathrm{x}} \mathrm{Te}$ and $\mathrm{Sn}_{1-\mathrm{x}} \mathrm{Sr}_{\mathrm{x}} \mathrm{Te}(\mathrm{x}<0.06)$ films were prepared by hot wall epitaxy. The ternary alloy films prepared in cation rich condition had hole concentration around $1 \times 10^{19} \mathrm{~cm}^{-3}$ with high mobility exceeding $2000 \mathrm{~cm}^{2} / \mathrm{V} \mathrm{s}$ at room temperature. Optical transmission spectra were also measured in the temperature range from 100 to $400 \mathrm{~K}$ and compared with theoretical calculations. Optical transmission spectra of the SnTe were simulated successfully assuming bumped band edge structures. A band inversion model was proposed for the $\mathrm{Sn}_{1-\mathrm{x}} \mathrm{Eu}_{\mathrm{x}} \mathrm{Te}$ and $\mathrm{Sn}_{1-\mathrm{x}} \mathrm{Sr}_{\mathrm{x}} \mathrm{Te}$ systems, and the optical transmission spectra were also simulated successfully assuming the band inversion model. (C) 2010 American Institute of Physics. [doi:10.1063/1.3446819]
\end{abstract}

\section{INTRODUCTION}

It is well known that the $\mathrm{Pb}_{1-\mathrm{x}} \mathrm{Sn}_{\mathrm{x}}$ Te system shows band inversion with the SnTe content $\mathrm{x}$, ${ }^{1}$ and the band gap $\left(E_{g}\right)$ of the $\mathrm{Pb}_{1-\mathrm{x}} \mathrm{Sn}_{\mathrm{x}} \mathrm{Te}$ with $\mathrm{x}<0.3$ has been studied by laser emission or optical transmission measurements. ${ }^{2}$ The materials are useful for infrared device applications such as infrared lasers and detectors. ${ }^{2-4}$ On the other hand, alloys with high Sn content have not been studied well because they show very high hole concentration. Typical SnTe films have carrier concentration as high as $10^{20} \mathrm{~cm}^{-3}$, and mobility as high as $200 \mathrm{~cm}^{2} / \mathrm{V}$ s. The hole concentration can be decreased by growing the films by cation rich conditions or adding $\mathrm{Bi}$ donors. ${ }^{5,6}$ Recently we prepared $\mathrm{Sn}_{1-\mathrm{x}} \mathrm{Eu}_{\mathrm{x}} \mathrm{Te}$ films and EuTe/ SnTe superlattices by depositing SnTe and Eu simultaneously or alternately. ${ }^{7}$ The $\mathrm{Sn}_{1-\mathrm{x}} \mathrm{Eu}_{\mathrm{x}} \mathrm{Te}$ films and superlattices showed hole concentration as high as $1 \times 10^{19} \mathrm{~cm}^{-3}$, and very high carrier mobility above $2000 \mathrm{~cm}^{2} / \mathrm{V} \mathrm{s}$ at room temperature. Figure 1 shows the band gaps of $\mathrm{Pb}_{1-x} \mathrm{Sn}_{\mathrm{x}} \mathrm{Te}$ and $\mathrm{Pb}_{1-x} \mathrm{Eu}_{\mathrm{x}}$ Te ternary alloys. ${ }^{8}$ The band gap of $\mathrm{Pb}_{1-x} \mathrm{Sn}_{\mathrm{x}} \mathrm{Te}$ decreases with the alloy content and shows a band inversion. Since the exact band gap of $\mathrm{Pb}_{1-\mathrm{x}} \mathrm{Sn}_{\mathrm{x}} \mathrm{Te}$ with high SnTe content was not clear, the band gap was drawn by linear extrapolation of the band gap of the $\mathrm{Pb}_{1-\mathrm{x}} \mathrm{Sn}_{\mathrm{x}} \mathrm{Te}$ with $\mathrm{x}<0.3$. Figure 2 shows two kinds of band inversion models of the $\mathrm{Pb}_{1-\mathrm{x}} \mathrm{Sn}_{\mathrm{x}} \mathrm{Te}$ which have been proposed before. ${ }^{1}$ In the model in Fig. 2(a), band structure of SnTe can be expressed by simple two-band energy-wave number $(E-\mathbf{k})$ relationship. On the other hand, band structure of SnTe has a bump around L-point of Brillouin zone in Fig. 2(b) as expected by empirical pseudopotential and $\mathbf{k} \cdot \mathbf{p}$ perturbation calculations. ${ }^{9,10}$ The band gap of $\mathrm{Pb}_{1-\mathrm{x}} \mathrm{Eu}_{\mathrm{x}} \mathrm{Te}$ as well as $\mathrm{Pb}_{1-\mathrm{x}} \mathrm{Sr}_{\mathrm{x}} \mathrm{Te}$ increases rapidly with the alloy content as shown in Fig. 1. Considering the band inversion in the $\mathrm{Pb}_{1-\mathrm{x}} \mathrm{Sn}_{\mathrm{x}} \mathrm{Te}$, band gaps of the $\mathrm{Sn}_{1-\mathrm{x}} \mathrm{Eu}_{\mathrm{x}} \mathrm{Te}$ and $\mathrm{Sn}_{1-\mathrm{x}} \mathrm{Sr}_{\mathrm{x}} \mathrm{Te}$ may also show band inversions with the $\mathrm{Eu}$ and $\mathrm{Sr}$ content. To clarify the band structures of

\footnotetext{
${ }^{a)}$ Author to whom correspondence should be addressed. Electronic mail: tdaishi@ipc.shizuoka.ac.jp.
}

the SnTe and $\mathrm{SnTe}$ based alloys, we prepared $\mathrm{Sn}_{1-\mathrm{x}} \mathrm{Eu}_{\mathrm{x}} \mathrm{Te}$ and $\mathrm{Sn}_{1-\mathrm{x}} \mathrm{Sr}_{\mathrm{x}} \mathrm{Te}$ films, and measured electrical and optical properties.

\section{ELECTRICAL PROPERTIES}

The $\mathrm{Sn}_{1-\mathrm{x}} \mathrm{Eu}_{\mathrm{x}} \mathrm{Te}$ and $\mathrm{Sn}_{1-\mathrm{x}} \mathrm{Sr}_{\mathrm{x}} \mathrm{Te}(\mathrm{x} \sim 0.02)$ films were prepared by simultaneous deposition of $\mathrm{SnTe}, \mathrm{Eu}$, and $\mathrm{Sr}$ on $\mathrm{BaF}_{2}(111)$ substrate using hot wall epitaxy system. ${ }^{7,8}$ Low carrier concentration SnTe film with $\mathrm{p}=2 \times 10^{19} \mathrm{~cm}^{-3}$ was also prepared by $\mathrm{Sb}$ donor doping. Substrate temperature during growth was $300{ }^{\circ} \mathrm{C}$. SnTe and Eu source temperatures for $\mathrm{Sn}_{1-\mathrm{x}} \mathrm{Eu}_{\mathrm{x}} \mathrm{Te}$ growth were about $500{ }^{\circ} \mathrm{C}$ and $470-500{ }^{\circ} \mathrm{C}$, respectively. The $\mathrm{Sr}$ source temperature for $\mathrm{Sn}_{1-\mathrm{x}} \mathrm{Sr}_{\mathrm{x}} \mathrm{Te}$ growth was comparable with the Eu source temperature. Growth rate of the films were about $1 \mathrm{~nm} / \mathrm{s}$. The $\mathrm{Sn}_{1-\mathrm{x}} \mathrm{Eu}_{\mathrm{x}} \mathrm{Te}$ and $\mathrm{Sn}_{1-\mathrm{x}} \mathrm{Sr}_{\mathrm{x}} \mathrm{Te}$ films with hole concentration around $1 \times 10^{19} \mathrm{~cm}^{-3}$ were obtained for $\mathrm{x} \geq 0.01$. Figure 3 shows dependence of the lattice constants of $\mathrm{Sn}_{1-\mathrm{x}} \mathrm{Eu}_{\mathrm{x}} \mathrm{Te}$ and $\mathrm{Sn}_{1-\mathrm{x}} \mathrm{Sr}_{\mathrm{x}} \mathrm{Te}$ films on the EuTe and SrTe contents. The EuTe and $\mathrm{SrTe}$ contents were determined from energy dispersive $\mathrm{x}$-ray spectroscopy measurement. Standard samples were not used to determine the absolute value of the Eu and Sr contents, and errors of the $\mathrm{Eu}$ and $\mathrm{Sr}$ contents are considered to be about $0.5 \%$. Lattice constants of the $\mathrm{Sn}_{1-\mathrm{x}} \mathrm{Eu}_{\mathrm{x}} \mathrm{Te}$ and $\mathrm{Sn}_{1-\mathrm{x}} \mathrm{Sr}_{\mathrm{x}} \mathrm{Te}$ were determined by $2 \theta-\theta$ x-ray diffraction mea-

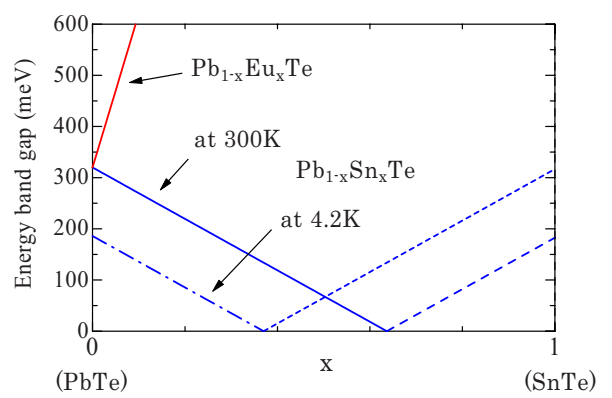

FIG. 1. (Color online) Band gaps of PbTe based alloys. $\mathrm{Pb}_{1-\mathrm{x}} \mathrm{Sn}_{\mathrm{x}} \mathrm{Te}$ shows band inversion and band gap of $\mathrm{Pb}_{1-\mathrm{x}} \mathrm{Eu}_{\mathrm{x}} \mathrm{Te}$ increases with the alloy content. 


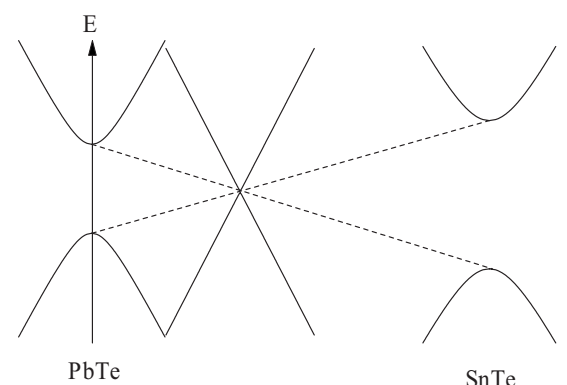

(a)

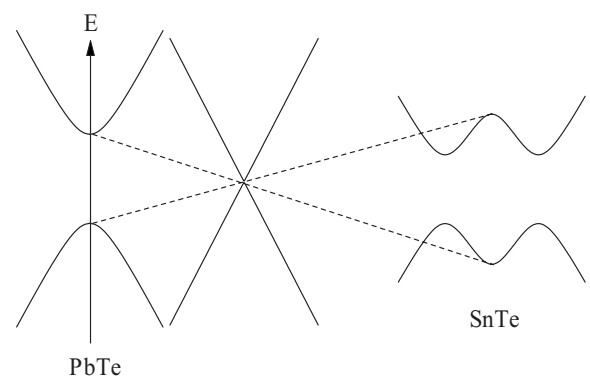

(b)

FIG. 2. Band inversion models of PbSnTe: (a) simple two band model and (b) bumped model.

surement, in which the lattice constants were calculated by the deviations of (222) reflection peaks from that of $\mathrm{BaF}_{2}$ substrate. Lattice constants of the $\mathrm{Sn}_{1-\mathrm{x}} \mathrm{Eu}_{\mathrm{x}} \mathrm{Te}$ and $\mathrm{Sn}_{1-\mathrm{x}} \mathrm{Sr}_{\mathrm{x}}$ Te increased linearly for $\mathrm{x}<0.1$, and lattice constant of $\mathrm{Sn}_{1-\mathrm{x}} \mathrm{Eu}_{\mathrm{x}}$ Te obeyed Vegard's law.

In the electrical property, films with Eu or $\mathrm{Sr}$ contents around $1 \%$ gave highest mobility, owing to the decrease in carrier concentration. Figure 4 shows dependence of hole mobility on hole concentration for the $\mathrm{Sn}_{1-\mathrm{x}} \mathrm{Eu}_{\mathrm{x}} \mathrm{Te}$ and $\mathrm{Sn}_{1-\mathrm{x}} \mathrm{Sr}_{\mathrm{x}} \mathrm{Te}(\mathrm{x} \leq 0.02)$ films. The decrease in hole concentration resulted in high hole mobility, and films with mobility higher than $2000 \mathrm{~cm}^{2} / \mathrm{V} \mathrm{s}$ were obtained both for the $\mathrm{Sn}_{1-\mathrm{x}} \mathrm{Eu}_{\mathrm{x}} \mathrm{Te}$ and $\mathrm{Sn}_{1-\mathrm{x}} \mathrm{Sr}_{\mathrm{x}} \mathrm{Te}$ films. Figure 5 shows temperature dependence of carrier concentration and mobility for a $\mathrm{Sn}_{1-\mathrm{x}} \mathrm{Eu}_{\mathrm{x}} \mathrm{Te}$ film $(\mathrm{x} \approx 0.01)$. The carrier concentration was independent of temperature, and low temperature mobility was restricted to less than $10000 \mathrm{~cm}^{2} / \mathrm{V} \mathrm{s}$ probably owing to alloy and vacancy scatterings.

\section{OPTICAL PROPERTIES}

The SnTe has direct gaps near the L-points of Brillouin zone. However, the detail of band edge structure has not

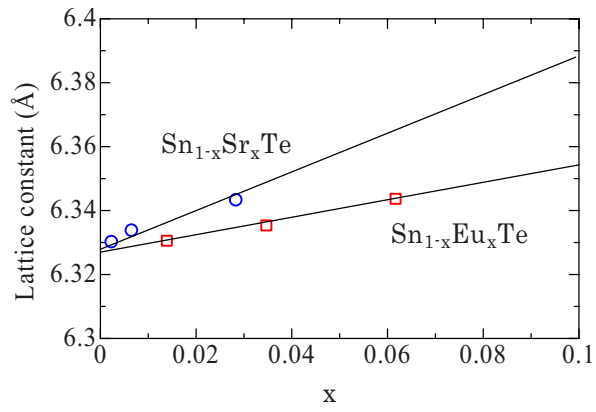

FIG. 3. (Color online) Dependence of the lattice constants of $\mathrm{Sn}_{1-\mathrm{x}} \mathrm{Eu}_{\mathrm{x}} \mathrm{Te}$ and $\mathrm{Sn}_{1-\mathrm{x}} \mathrm{Sr}_{\mathrm{x}} \mathrm{Te}$ films on the EuTe and SrTe contents.

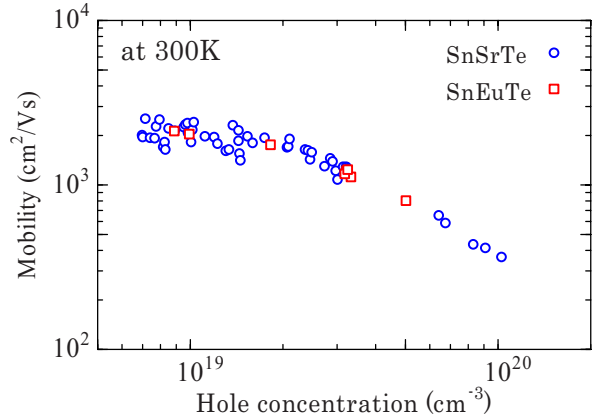

FIG. 4. (Color online) Dependence of hole mobility on hole concentration for $\mathrm{Sn}_{1-\mathrm{x}} \mathrm{Eu}_{\mathrm{x}} \mathrm{Te}$ and $\mathrm{Sn}_{1-\mathrm{x}} \mathrm{Sr}_{\mathrm{x}} \mathrm{Te}(\mathrm{x} \sim 0.01)$ alloys. The hole mobilities increase remarkably with the decrease in hole concentration.

been studied owing to the high carrier concentration. ${ }^{11} \mathrm{Ab}$ sorption coefficient of direct gap IV-VI compound semiconductor is given by ${ }^{12}$

$$
\alpha_{0}(\hbar \omega)=A \frac{D_{J}(\hbar \omega)}{\hbar \omega},
$$

where $A$ is a constant, $D_{J}(\hbar \omega)$ is the joint density of states between valence and conduction bands, and $\omega$ is a incident phonon frequency. Considering the carrier and temperature effects on the interband absorption coefficient, known as Burstein-Moss effect, the absorption coefficient for symmetrical band is modified as ${ }^{12}$

$$
\alpha(\hbar \omega)=\frac{\alpha_{0}(\hbar \omega)}{1+\exp \left(\frac{2 E_{V}-2 E_{F}-\hbar \omega+E_{g}}{2 k T}\right)},
$$

where $E_{V}$ and $E_{F}$ are valence band edge energy and Fermi level, respectively.

If we assume a simple two-band $E-\mathbf{k}$ nonparabolicity given by

$$
\left(E-\frac{E_{g}}{2}\right)\left(E+\frac{E_{g}}{2}\right)=\left(\frac{\hbar^{2} k_{l}^{2}}{2 m_{l}}+\frac{\hbar^{2} k_{t}^{2}}{2 m_{t}}\right) E_{g},
$$

where $k_{l}$ and $k_{t}$ are wave numbers of carrier in longitudinal and transverse directions, respectively, $m_{l}$ and $m_{t}$ are corresponding effective masses and $E$ is measured from the midpoint between the valence and conduction band edge energies. Then the density of states and joint density of states for the nonparabolic bands are given by

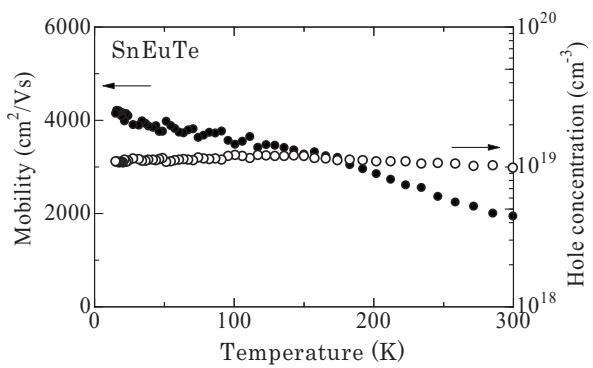

FIG. 5. Dependence of hole mobility and hole concentration on temperature for a $\mathrm{Sn}_{1-\mathrm{x}} \mathrm{Eu}_{\mathrm{x}} \mathrm{Te}$ film. 


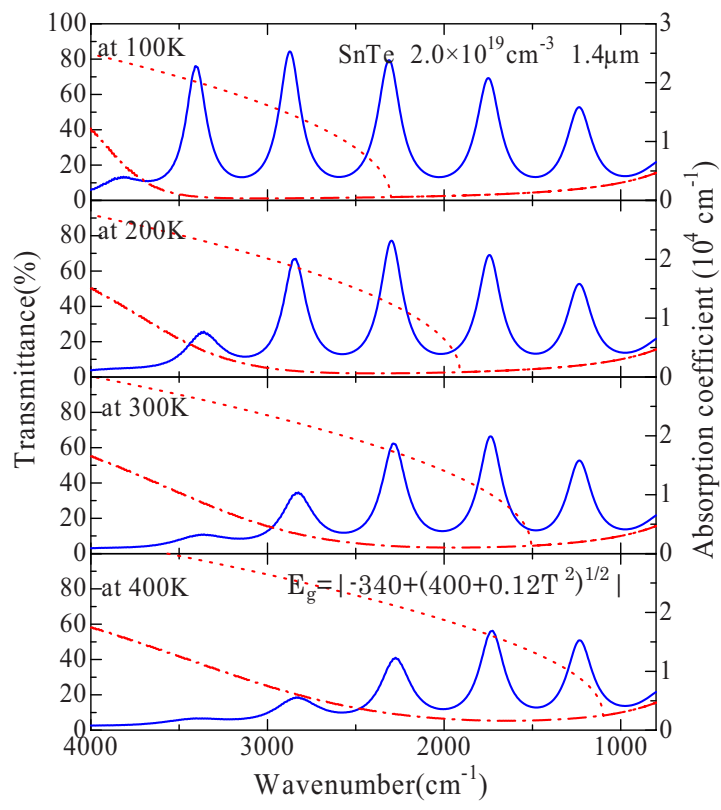

FIG. 6. (Color online) Temperature dependence of theoretical optical transmission spectra (solid lines) of SnTe film with hole concentration of 2 $\times 10^{19} \mathrm{~cm}^{-3}$ assuming simple two band model in Fig. 2(a). Dashed-dotted and dotted lines are corresponding absorption coefficients and absorption coefficients for zero carrier concentration, respectively.

$$
D(E)=\frac{1}{4 \pi^{3}} \frac{\partial V_{k}}{\partial E}=\frac{2 \sqrt{2} M m_{t} m_{l}^{1 / 2} E}{\pi^{2} \hbar^{3} E_{g}^{3 / 2}} \sqrt{\left(E-\frac{E_{g}}{2}\right)\left(E+\frac{E_{g}}{E}\right)},
$$

and

$$
\begin{aligned}
D_{J}(\hbar \omega) & =\frac{1}{4 \pi^{3}} \frac{\partial V_{k}}{\partial(\hbar \omega)} \\
& =\frac{\sqrt{2} M m_{t} m_{l}^{1 / 2} \omega}{4 \pi^{2} \hbar^{2} E_{g}^{3 / 2}} \sqrt{\left(\hbar \omega-E_{g}\right)\left(\hbar \omega+E_{g}\right)},
\end{aligned}
$$

where $V_{k}$ is the k-space volume surrounded by constant energy surfaces, $M(=4)$ is the number of equivalent valleys.

Tsang et $a l .{ }^{9}$ proposed a bumped band edge structure by empirical pseudopotential calculation, in which $E-\mathbf{k}$ relationship is parabolic along $\Lambda$ direction (longitudinal direction) and it is bumped perpendicular to the $\Lambda$ direction (transverse direction). Similar band structure had also been proposed by Rabii. ${ }^{10}$ In this band structure, the constant energy surface near the band edge has a doughnut-shape and the density of states has a large value with a step at the band edge. To investigate the band structure, we first measured optical transmission spectra of SnTe and compared with theoretical values.

Figure 6 shows theoretical optical transmission spectra for SnTe with carrier concentration of $2 \times 10^{19} \mathrm{~cm}^{-3}$ at 100 $\mathrm{K}, 200 \mathrm{~K}, 300 \mathrm{~K}$, and $400 \mathrm{~K}$, respectively, assuming the $E-\mathbf{k}$ relationship given by Eq. (3). Corresponding absorption coefficients and absorption coefficients for zero carrier concentration film are also indicated as dashed-dotted and dotted lines, respectively. To calculate the optical transmission

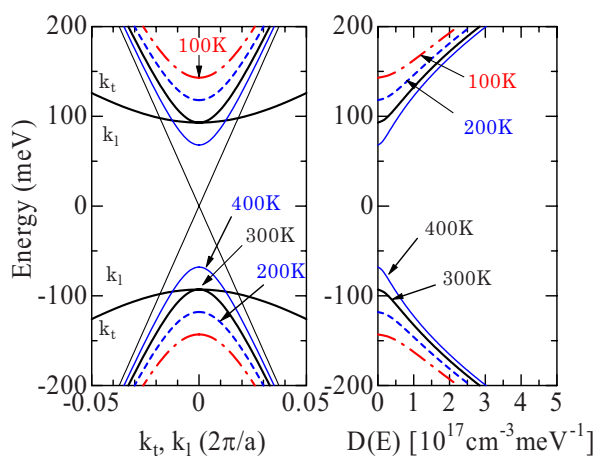

FIG. 7. (Color online) Band edge structures and corresponding densities of states used to calculate the theoretical spectra in Fig. 6.

spectra, we assumed band structures and corresponding densities of states shown in Fig. 7 We assumed the band gap of SnTe varies as

$$
E_{g}(\mathrm{SnTe})=\left|-340+\left(400+0.256 T^{2}\right)^{1 / 2}\right|(\mathrm{meV}),
$$

which is deduced from the analogy of the band gap of $\mathrm{Pb}_{1-\mathrm{x}} \mathrm{Sn}_{\mathrm{x}} \mathrm{Te}(\mathrm{x}<0.3){ }^{13}$ In Eq. (6), the band gap varies as $\mathrm{d} E_{g} / \mathrm{d} T=-0.5 \mathrm{meV} / \mathrm{K}$ for $T \geq 100 \mathrm{~K}$. Though there are no reliable data on the effective mass of $\mathrm{SnTe}$, we assumed the band edge effective masses are proportional to the band gap as expected from simple two band model with the values $m_{t}=0.024 m_{0} E_{g} / 186$ and $m_{l}=0.24 m_{0} E_{g} / 186$, respectively, where $m_{0}$ is free electron mass. The values are consistent with the effective mass data used to calculate the tunneling properties of SnTe by Tsu et al. ${ }^{14}$ If the band edge structure is given by simple two-band model in Fig. 2(a), a large absorption-edge shift with temperature is expected by both Burstein-Moss effect and negative temperature dependence of the band gap.

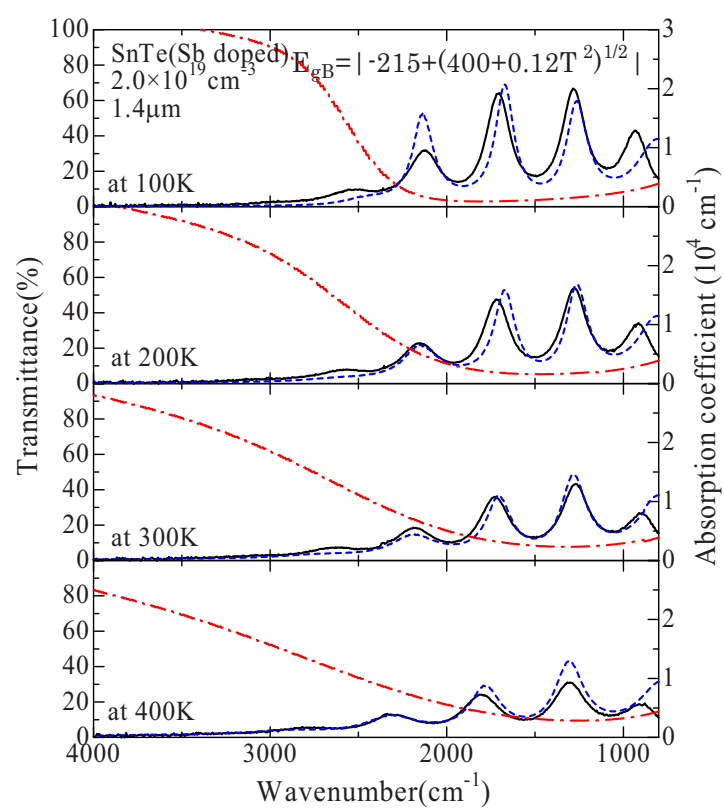

FIG. 8. (Color online) Optical transmission spectra (solid line) of Sb doped SnTe with hole concentration $2 \times 10^{19} \mathrm{~cm}^{-3}$ at $100,200,300$, and $400 \mathrm{~K}$, and simulated spectra (dashed lines) and corresponding absorption coefficients (dashed-dotted lines) assuming the bumped band model in Fig. 9. 


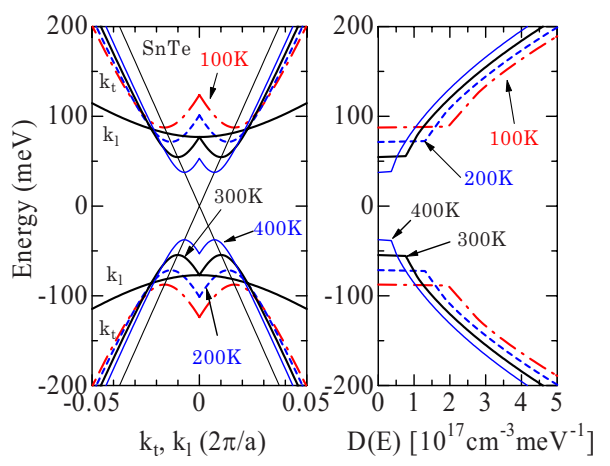

FIG. 9. (Color online) Bumped band edge structures and corresponding densities of states of SnTe film obtained by the simulation between experimental and theoretical spectra.
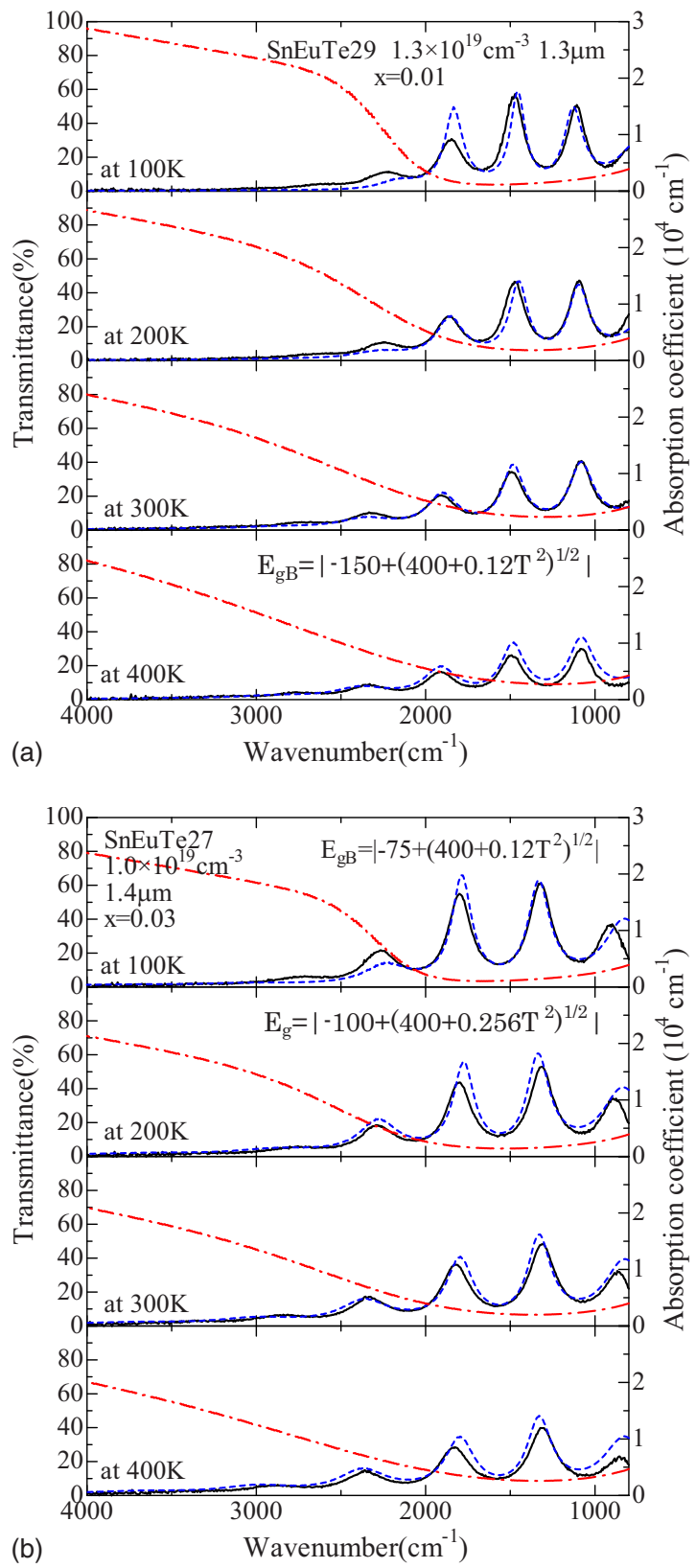

However, no significant shift of the absorption edge was observed in the experimental ones as shown by solid lines in Fig. 8, as if the band gap had positive temperature dependence. In order to explain the experimental spectra, we simulated the spectra (dashed lines) and corresponding absorption coefficients (dashed-dotted lines) shown in Fig. 8 assuming bumped band edge structures in the following way. In the bumped structures, we assumed the same $E-\mathbf{k}$ relationships given by Eq. (3) along the $\Lambda$ axis (longitudinal direction). Along transverse direction, we assumed the same $E-\mathbf{k}$ relationship just at the bottom of conduction band and top of valence band, beside the L-point. We also assumed the position of the extremum exists on the asymptote of Eq. (3) in the zero-gap limit, as indicated in Fig. 9. Very good agreements between the experimental and simulated spectra were obtained assuming the band structures and corresponding

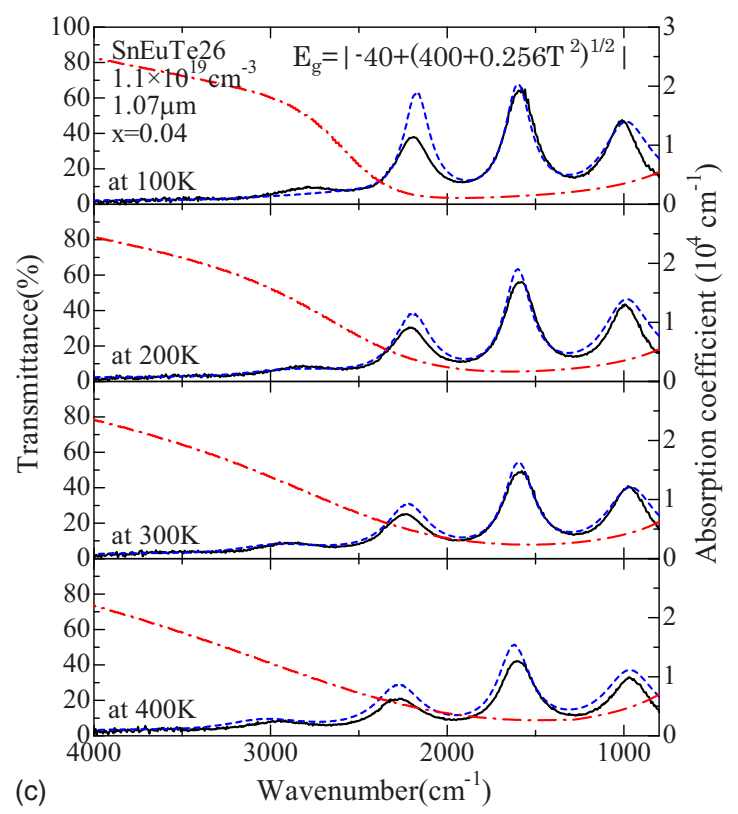

(c)

FIG. 10. (Color online) Experimental (solid line) and simulated (dashed line) optical transmission spectra for (a) $\mathrm{Sn}_{0.99} \mathrm{Eu}_{0.01} \mathrm{Te}$, (b) $\mathrm{Sn}_{0.97} \mathrm{Eu}_{0.03} \mathrm{Te}$, and (c) $\mathrm{Sn}_{0.96} \mathrm{Eu}_{0.04} \mathrm{Te}$ films at 100, 200,300, and $400 \mathrm{~K}$. Corresponding absorption coefficients are indicated by dotted-dashed lines. 


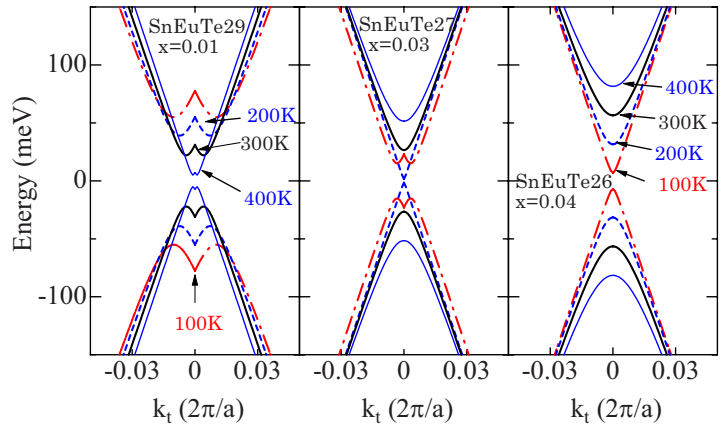

FIG. 11. (Color online) Simulated band edge structures of $\mathrm{Sn}_{1-\mathrm{x}} \mathrm{Eu}_{\mathrm{x}} \mathrm{Te}$ films from the optical spectra in Fig. 10.

densities of states shown in the Fig. 9. In the simulation, bumped band gap at the smallest point was assumed to vary as

$$
E_{g}(\mathrm{SnTe})=\left|-215+\left(400+0.12 T^{2}\right)^{1 / 2}\right|(\mathrm{meV}),
$$

where $\mathrm{d} E_{g} / \mathrm{d} T=-0.35 \mathrm{meV} / \mathrm{K}$ for $T \geq 100 \mathrm{~K}$. In this assumption, temperature dependence of the band gap at the L-point becomes $\mathrm{d} E_{g} / \mathrm{d} T \approx-0.45 \mathrm{meV} / \mathrm{K}$ which is comparable with that in Eq. (6).

We analyzed optical transmission properties of the $\mathrm{Sn}_{1-\mathrm{x}} \mathrm{Eu}_{\mathrm{x}} \mathrm{Te}$ and $\mathrm{Sn}_{1-\mathrm{x}} \mathrm{Sr}_{\mathrm{x}} \mathrm{Te}$ films accordingly. Here we assumed the bumped and simple band structures before and after band inversion regions, respectively. Figure 10 shows optical transmission spectra (solid lines) of $\mathrm{Sn}_{1-\mathrm{x}} \mathrm{Eu}_{\mathrm{x}} \mathrm{Te}$ films for (a) $\mathrm{x}=0.01$, (b) $\mathrm{x}=0.03$, and (c) $\mathrm{x}=0.04$ at 100, 200, 300, and $400 \mathrm{~K}$ with the simulated spectra (dashed lines) assuming theoretical interband absorption coefficients taking the Burstein-Moss effect into account and free carrier absorption which increases proportionally to the wavelength square. Corresponding absorption coefficients are also indicated by dashed-dotted lines. Band edge structures of $\mathrm{Sn}_{1-\mathrm{x}} \mathrm{Eu}_{\mathrm{x}} \mathrm{Te}$ obtained by the simulations are shown in Fig. 11. In the bumped region (before band inversion), we assumed the band gap with same temperature dependence term of Eq. (7) as

$$
E_{g}(x)=\left|E_{B}(x)+\left(400+0.12 T^{2}\right)^{1 / 2}\right|(\mathrm{meV}),
$$

where $E_{B}(x)$ is a constant depending on the composition $\mathrm{x}$. In this region the band gap has a temperature dependence of $-0.35 \mathrm{meV} / \mathrm{K}$ for $T \geq 100 \mathrm{~K}$. On the other hand, in the region after band inversion, band gap was of the form with same temperature dependence term of Eq. (6) as

$$
E_{g}(x)=\left|E_{0}(x)+\left(400+0.256 T^{2}\right)^{1 / 2}\right|(\mathrm{meV}),
$$

where $E_{0}(x)$ is another constant depending on the composition $\mathrm{x}$ and $\mathrm{d} E_{g} / \mathrm{d} T=0.5 \mathrm{meV} / \mathrm{K}$ for $T \geq 100 \mathrm{~K}$.

Figure 12 shows optical transmission spectra of $\mathrm{Sn}_{1-\mathrm{x}} \mathrm{Sr}_{\mathrm{x}}$ Te films for (a) $\mathrm{x}=0.01$ and (b) $\mathrm{x}=0.03$ at 100, 200, 300 , and $400 \mathrm{~K}$ with the simulated spectra (dashed lines) and corresponding absorption coefficients (dashed-dotted lines). Band edge structures obtained by the simulations are shown in Fig. 13. Very good agreements between experimental and
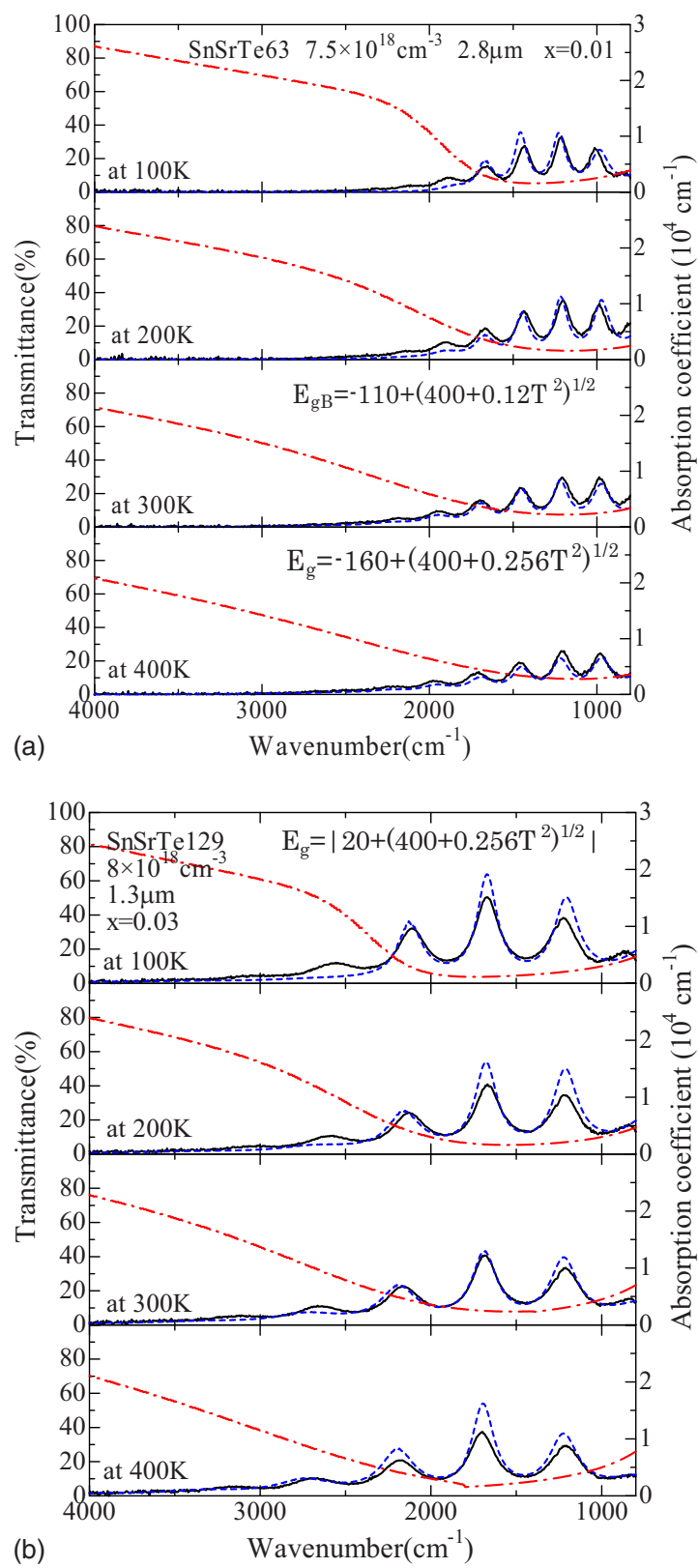

FIG. 12. (Color online) Experimental (solid line) and simulated (dashed line) optical transmission spectra for (a) $\mathrm{Sn}_{0.99} \mathrm{Sr}_{0.01} \mathrm{Te}$, (b) $\mathrm{Sn}_{0.97} \mathrm{Sr}_{0.03} \mathrm{Te}$ films at 100, 200, 300, and $400 \mathrm{~K}$. Corresponding absorption coefficients are indicated by dotted-dashed lines.

simulated spectra were also obtained with the same assumptions used in $\mathrm{Sn}_{1-\mathrm{x}} \mathrm{Eu}_{\mathrm{x}} \mathrm{Te}$ films.

Figure 14 shows the determined band gap of $\mathrm{Sn}_{1-\mathrm{x}} \mathrm{Eu}_{\mathrm{x}} \mathrm{Te}$ and $\mathrm{Sn}_{1-\mathrm{x}} \mathrm{Sr}_{\mathrm{x}} \mathrm{Te}$ from the simulations at $300 \mathrm{~K}$. The solid line for the $\mathrm{Sn}_{1-\mathrm{x}} \mathrm{Eu}_{\mathrm{x}} \mathrm{Te}$ corresponds to $E_{g}(x)=\mid-110$ $+5500 x \mid(\mathrm{meV})$, and dashed line for $\mathrm{Sn}_{1-\mathrm{x}} \mathrm{Sr}_{\mathrm{x}} \mathrm{Te}$ corresponds to $E_{g}(x)=|-110+7700 x|(\mathrm{meV})$. After band inversion, it is observed that the band gap increases proportionally to the EuTe content for the $\mathrm{Sn}_{1-\mathrm{x}} \mathrm{Eu}_{\mathrm{x}} \mathrm{Te}$ films.

\section{CONCLUSION}

The $\mathrm{Sn}_{1-\mathrm{x}} \mathrm{Eu}_{\mathrm{x}} \mathrm{Te}$ and $\mathrm{Sn}_{1-\mathrm{x}} \mathrm{Sr}_{\mathrm{x}} \mathrm{Te}(\mathrm{x}<0.06)$ films were prepared by hot wall epitaxy, and electrical and optical properties were measured. The ternary alloy films prepared in cation rich condition had hole concentration around 1 


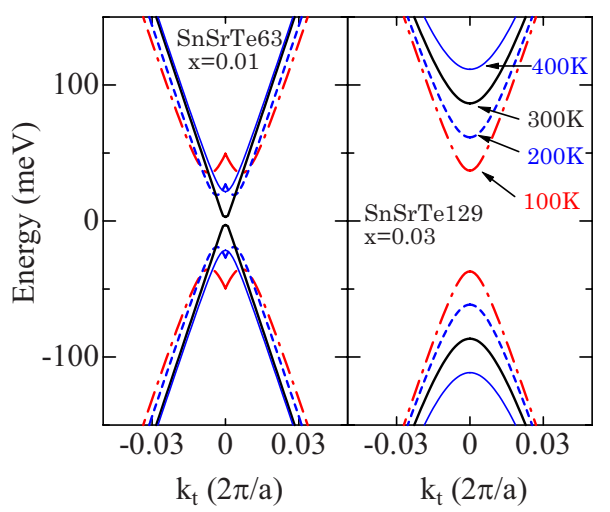

FIG. 13. (Color online) Simulated band edge structures of $\mathrm{Sn}_{1-\mathrm{x}} \mathrm{Sr}_{\mathrm{x}} \mathrm{Te}$ films from the optical spectra in Fig. 12.

$\times 10^{19} \mathrm{~cm}^{-3}$ with high mobility exceeding $2000 \mathrm{~cm}^{2} / \mathrm{V} \mathrm{s}$ at room temperature. Optical transmission spectra were measured in the temperature range from 100 to $400 \mathrm{~K}$ to determine the band gaps of the alloys, and compared with theoretical calculations taking Burstein-Moss effect into account. Band inversions similar to $\mathrm{Pb}_{1-\mathrm{x}} \mathrm{Sn}_{\mathrm{x}}$ Te system were observed in the $\mathrm{Sn}_{1-x} \mathrm{Eu}_{\mathrm{x}} \mathrm{Te}$ and $\mathrm{Sn}_{1-\mathrm{x}} \mathrm{Sr}_{\mathrm{x}} \mathrm{Te}$ systems. In the region after the band inversion, the band gaps of the $\mathrm{Sn}_{1-\mathrm{x}} \mathrm{Eu}_{\mathrm{x}} \mathrm{Te}$ and $\mathrm{Sn}_{1-\mathrm{x}} \mathrm{Sr}_{\mathrm{x}} \mathrm{Te}$ increased with the contents and the optical transmission spectra were explained by the simple two band model. On the other hand, the optical transmission spectra of the alloys before band inversion were explained well with bumped band edge structures. For the $\mathrm{Sn}_{1-x} \mathrm{Eu}_{\mathrm{x}} \mathrm{Te}$ and $\mathrm{Sn}_{1-\mathrm{x}} \mathrm{Sr}_{\mathrm{x}} \mathrm{Te}$, room temperature band gap varied with the EuTe content $\mathrm{x}$ as $E_{g}(x)=|-110+5500 x|(\mathrm{meV})$ and $E_{g}(x)$ $=|-110+7700 x|(\mathrm{meV})$, respectively.

\section{ACKNOWLEDGMENTS}

This work was financially supported by Suzuki foundation, and partly supported by Grants-in-Aid for Scientific Re-

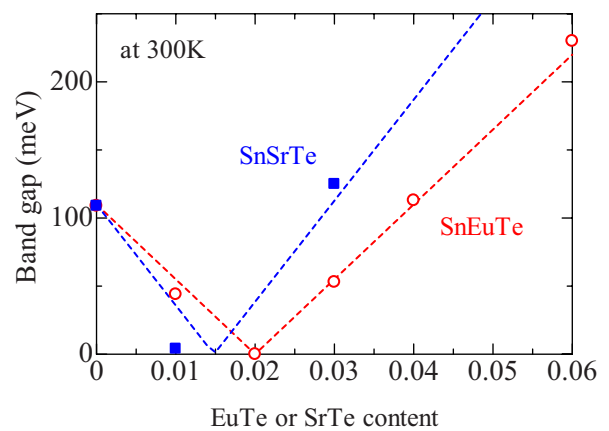

FIG. 14. (Color online) Experimental band gaps of $\mathrm{Sn}_{1-\mathrm{x}} \mathrm{Eu}_{\mathrm{x}} \mathrm{Te}$ and $\mathrm{Sn}_{1-\mathrm{x}} \mathrm{Sr}_{\mathrm{x}} \mathrm{Te}$ films at $300 \mathrm{~K}$.

search (Grant no. 21360336) from the Japan Society for the Promotion of Science.

${ }^{1}$ J. O. Dimmock, in Physics of Semimetals and Narrow Gap Semiconductors, edited by D. L. Carter and R. T. Bate (Pergamon, Oxford, 1971), p. 363.

${ }^{2}$ J. F. Butler and T. C. Harman, IEEE J. Quantum Electron. 5, 50 (1969).

${ }^{3}$ D. R. Khokhlov, I. I. Ivanchik, S. N. Raines, D. M. Watson, and J. L. Pipher, Appl. Phys. Lett. 76, 2835 (2000).

${ }^{4}$ Y. Nishijima, J. Appl. Phys. 65, 935 (1989).

${ }^{5}$ H. R. Riedl, J. R. Dixon, and R. B. Schoolar, Phys. Rev. 162, 692 (1967). ${ }^{6}$ M. A. Tamor, H. Holloway, R. M. Ager, C. A. Gierczak, and R. O. Carter, J. Appl. Phys. 61, 1094 (1987).

${ }^{7}$ A. Ishida, T. Yamada, T. Tsuchiya, Y. Inoue, S. Takaoka, and T. Kita, Appl. Phys. Lett. 95, 122106 (2009).

${ }^{8}$ A. Ishida, S. Matsuura, M. Mizuno, Y. Sase, and H. Fujiyasu, J. Appl. Phys. 63, 4572 (1988).

${ }^{9}$ Y. W. Tsang and M. L. Cohen, Phys. Rev. B 3, 1254 (1971).

${ }^{10}$ S. Rabii, Phys. Rev. 182, 821 (1969).

${ }^{11}$ J. R. Burke, Jr. and H. R. Riedl, Phys. Rev. 184, 830 (1969).

${ }^{12}$ A. Ishida and H. Fujiyasu, Jpn. J. Appl. Phys., Part 2 24, L956 (1985).

${ }^{13}$ H. Preier, Appl. Phys. (Berlin) 20, 189 (1979).

${ }^{14}$ R. Tsu, W. E. Howard, and L. Esaki, Phys. Rev. 172, 779 (1968). 